\title{
A SCANNING ELECTRON MICROSCOPE STUDY OF CHANGES IN BABOON CERVICAL MUCUS DURING THE MENSTRUAL CYCLE
}

\author{
F. G. GHRÉTIEN, J. COHEN and A. PSYGHOYOS \\ Laboratoire de Physiologie de la Reproduction, \\ Centre National de la Recherche Scientifique, Equipe de Recherche 122, \\ Hôpital de Bicêtre, 94270 Kremlin-Bicêtre, France
}

(Received 23rd Fanuary 1974)

In primates, ruminants and some rodents, the semen is not ejaculated directly into the uterus but is deposited in the vagina. Mucus is elaborated and secreted in the upper part of the cervical canal in these species, and the canal can reasonably be supposed, therefore, to act both as a reservoir in which the spermatozoa are stored after copulation and as a selective cyclic filter, allowing the spermatozoa to enter the uterus only during the ovulatory period.

The theoretical spatial organization of human mucus micelles has been studied using the technique of nuclear magnetic resonance (Odeblad, 1968). Organized as a network of fibrils linked together by oblique or transverse bonds, the micelles show a "tricot-like macromolecular arrangement". During the ovulatory period, the meshes would enlarge in order to let the sperm cells penetrate and permit their migration towards the uterine cavity. During the luteal phase, the glycoprotein chains which constitute the frame of the mucoidal hydrogel would have a greater autonomy, and would be less frequently associated as fibrillar micelles, thus forming an impervious barrier to sperm cells. Odeblad (1969) distinguished two types of cervical mucus in women: the $\mathrm{E}$ type (oestrogenic), characterized by a parallel arrangement of the micelles, which forms the main part $(95 \%)$ of the cervical mucus secreted during the ovulatory period, and the $G$ type (gestagenic) in which the disaggregated micelles inter-mesh, forming a compact network. The latter is predominant in the mucus of the luteal phase.

Transmission electron microscopy (TEM) does not seem to be a suitable technique for studying the mucoidal structures (Chrétien, 1973). In fact, TEM studies of human and bovine cervical mucus give results which vary according to the author (Van Bruggen \& Kremer, 1970; Singer \& Reid, 1970; Elstein, Mitchell \& Syrett, 1971). A more appropriate technique for observation is offered by scanning electron microscopy which was recently used to produce the first three-dimensional pictures of the ultrastructure of human ovulatory cervical mucus and proved the reality of the 'tricot-like macromolecular gel arrangement' (Chrétien, Gernigon, David \& Psychoyos, 1973a, b).

Considering the taxonomic proximity of non-human primates and man, the 
glycoprotein structure of the cervical mucus of the female monkey is unlikely to be notably different from that in women.

The cervical secretion of the macaque monkey is abundant, but the sinuosity of its cervical canal makes it difficult to sample mucus from the endocervix (Graham, 1973). The baboon (Papio anubis), in which the cervical canal is rectilinear, was therefore selected for study of the cervical mucus in monkeys during the menstrual cycle.

Six baboons were selected for their good health and the regularity of their menstrual cycles. Each animal was followed for several months by daily record of the sexual skin development and menstruation. The samples of mucus were taken on different days during the cycle and correlated with the time of ovulation by the 1st day of detumescence of the sexual skin, which occurs on the 3rd day after ovulation in this species (Hendrickx \& Kraemer, 1968). The animals were anaesthetized by an intramuscular injection of Ketalar (Parke-Davis) at a dose of $0.5 \mathrm{mg} / \mathrm{kg}$ body weight. Mucus was recovered by aspiration using a dry cannula $(2.0 \mathrm{~mm})$ inserted into the cervical canal and attached to a $20-\mathrm{ml}$ disposable syringe. The samples of mucus were placed on a glass coverslip by slowly evacuating the cannula in order to avoid the formation of bubbles. This technique resulted in minimal mechanical stress and minimal distortion of structure. The samples were then immediately fixed in a cold solution of $2.5 \%$ glutaraldehyde in $0.1 \mathrm{M}$-Sörensen's phosphate buffer and the fixed samples were treated as previously reported (Chrétien et al., 1973a, b) and examined with a Cambridge Stereoscan microscope at $25 \mathrm{~kW}$.

Fourteen samples were taken during the ovulatory period, between 6 to 3 days before the onset of detumescence of the sexual skin. The alignment of the meshes was similar to that observed in the cervical mucus during the same period in women (Chrétien et al., 1973a, b). The glycoprotein filaments were also disposed according to a 'tricot-like macromolecular gel arrangement' in which the linear or disordered orientation of the fibrils seemed to depend on traction forces exerted on the mucus during its sampling. Red cells which were present in certain samples provided a standard for comparison of the relative dimensions of filaments and meshes (Pl. 1, Fig. 1). Three size classes of filaments could be observed: $\alpha$-, $\beta$ - and $\gamma$-filaments (2000 to $4000 \AA, 1000$ to $1500 \AA$ and 500 to $750 \AA$ in diameter, respectively-see Pl. 1, Fig. 2). The $\alpha$-filaments seemed to constitute the main structural support. The $\beta$-filaments were less frequent and the $\gamma$-filaments were rarely seen. These three classes of filaments were similar to those described in human cervical mucus, but the $\alpha$-filaments were thinner and the $\beta$-filaments less dense in the baboon. Most of the meshes of the loose network were large enough to permit the passage of sperm cells. The diameter of the head of a baboon spermatozoon is about $3 \mu \mathrm{m}$.

\section{EXPLANATION OF PLATE 1}

Fic. 1. Baboon cervical mucus of the ovulatory period. Some red cells $(4.5 \mu \mathrm{m}$ in diameter) can be distinguished to the right of the figure. $\times 3500$.

Frg. 2. Cervical mucus of the same animal, taken during the ovulatory period, showing the three sizes of filament: $\alpha$-filaments (large arrow), $\beta$-filaments (medium-sized arrow) and $\gamma$-filaments (small arrow). $\times 8800$. 


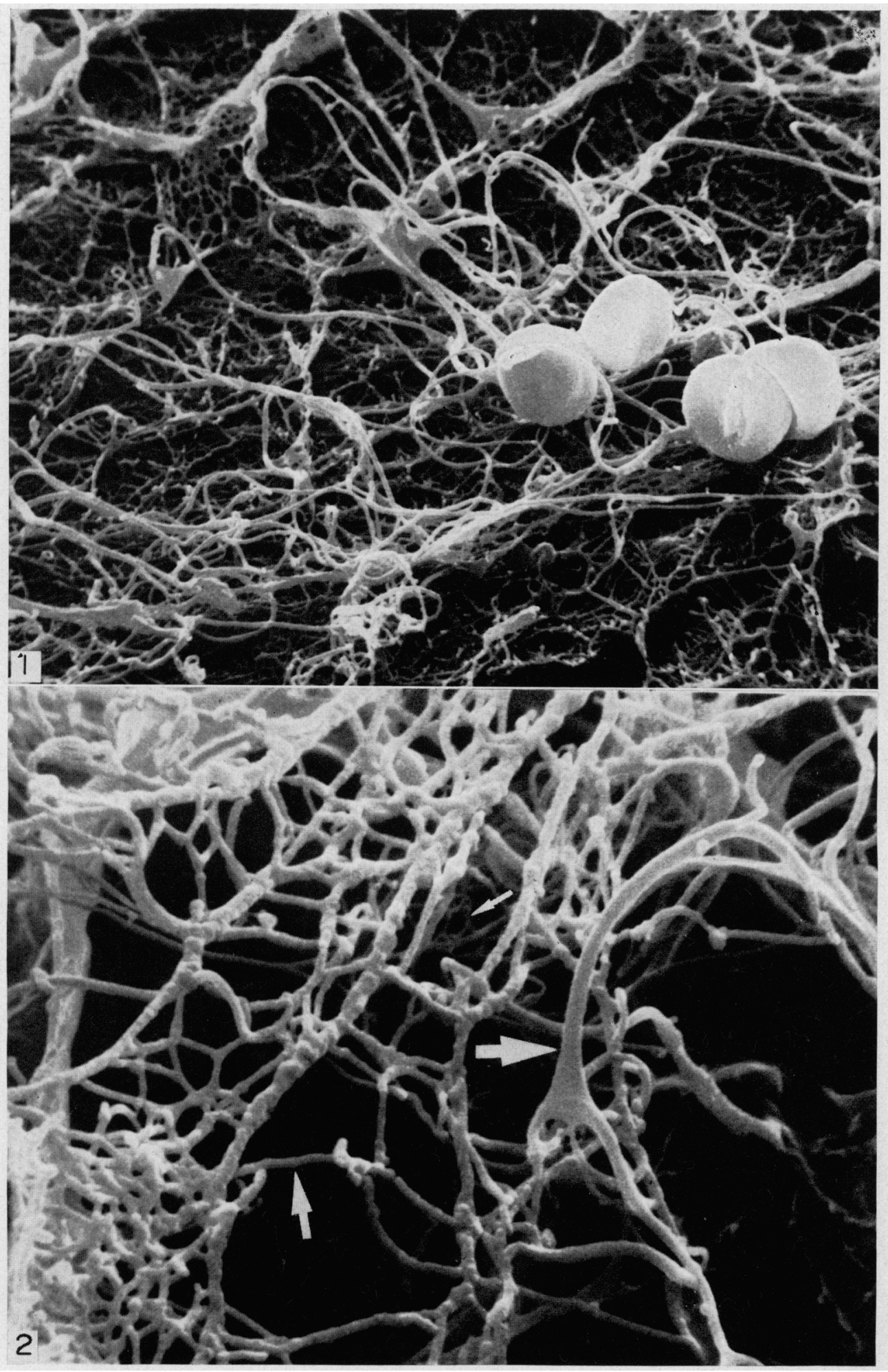




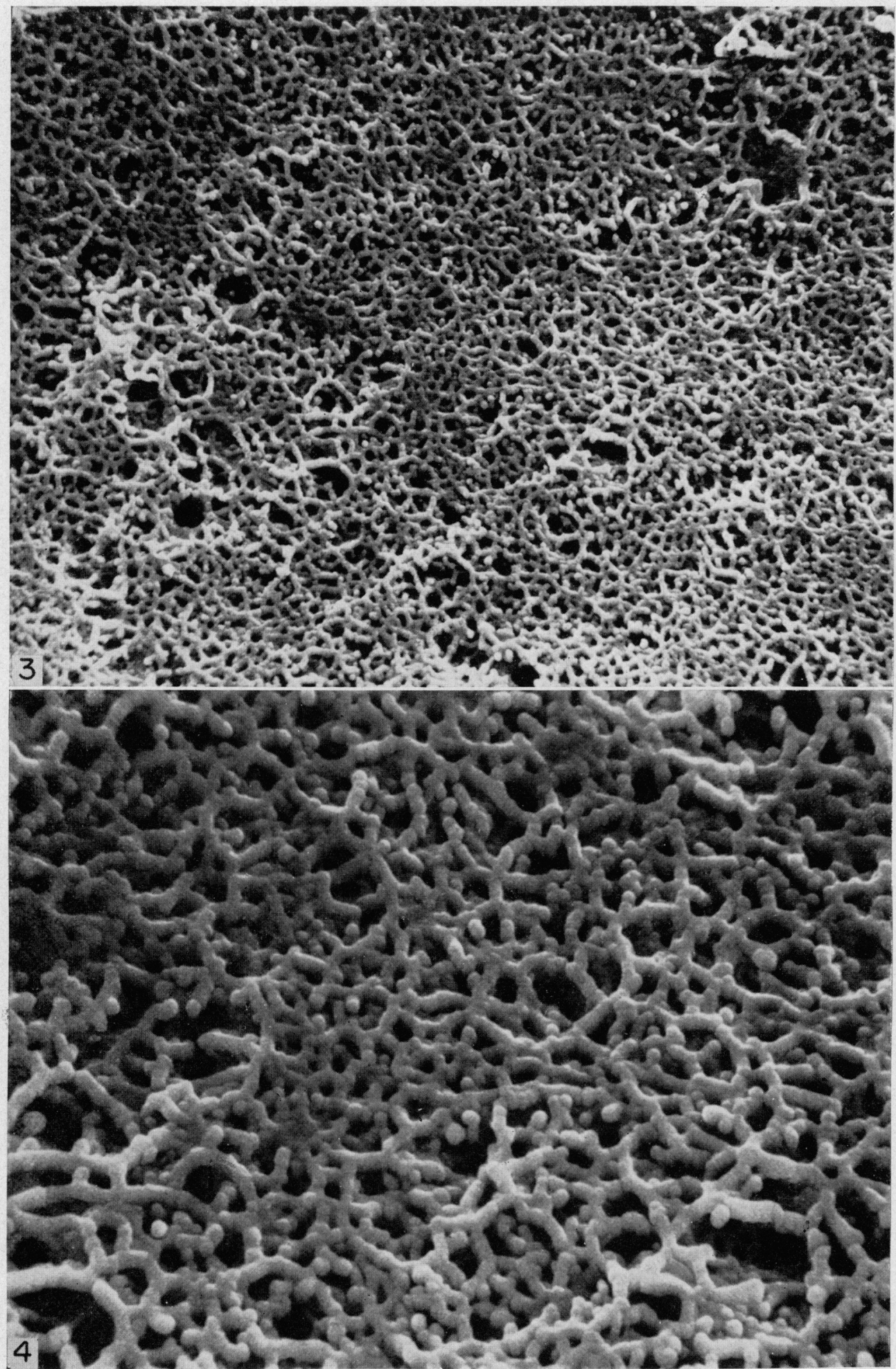


Sixteen samples of cervical mucus were taken during the luteal phase, 3 to 12 days from the beginning of detumescence. Separate filaments could no longer be observed and, in some places, the frame looked like a dense and extremely compact network (Pl. 2, Fig. 3). The filaments generally appeared with glomerular extremities. Their diameters were nearly identical ( 3000 to $4000 \AA)$ and it was almost impossible to distinguish the different size classes which were apparent during the ovulatory period (Pl. 2, Fig. 4).

Our observations indicate that the micellar structure of the cervical mucus during the menstrual cycle of the baboon undergoes changes which are similar to those which Odeblad (1969) suggested occurred in women. These changes, which concern especially the size of the meshes of the 'tricot-like arrangement', must certainly be related to the cyclic variations of the penetrability of cervical mucus by spermatozoa.

Scanning electron microscopy is thus revealed to be a technique of choice for the study of the cyclic changes of the ultrastructure of cervical mucus and therefore highly useful either for clinical research and diagnostic purposes or for experimental studies in non-human primates.

This work was supported by grants from the Ford Foundation and from the Population Council.

\section{REFERENGES}

Ghrétien, F. C. (1973) L'ultrastructure de la glaire cervicale. Contraception, Fertilité, Sexualité, 1, 9. Ghrétien, F. G., Gernigon, G., David, G. \& Psychoyos, A. (1973a) L'ultrastructure de la glaire cervicale humaine en microscopie électronique à balayage. Inl Gynéc. obstet. Biol. Reprod. 2, 341.

Ghrétien, F. G., Gernigon, G., David, G. \& Psychoyos, A. (1973b) The ultrastructure of human cervical mucus under scanning electron microscopy. Fert. Steril. 24, 746.

Elstein, M., Mrtchell, R. F. \& Syrett, J. T. (1971) Ultrastructure of cervical mucus. F. Obstet. Gynaec. Br. Commonw. 78, 180.

Graham, C. E. (1973) Functional microanatomy of the primate uterine cervix. In Handbook of Physiology, Endocrinology, vol. II, Part 2, Chap. 30. Am. Physiol. Soc., Washington.

Hendrickx, A. G. \& Kraemer, D. G. (1968) Preimplantation stages of baboon embryos (Papio sp.). Anat. Rec. 162, 111.

Odeblad, E. (1968) The functional structure of human cervical mucus. Acta obstet. gynec. scand. 47, Suppl. 1, 59.

Odeblad, E. (1969) Types of human cervical secretion. Acta europ. fertil. 1, 99.

Singer, A. \& ReID, B. L. (1970) The ultrastructure of cervical mucus. F. Reprod. Fert. 21, 377.

VAN BRUgGen, E. F. J. \& KREMER, J. (1970) Electron microscopy of bovine and human cervical mucus. Int. J. Fert. 15, 50 .

\section{EXPLANATION OF PLATE 2}

Fig. 3. Baboon cervical mucus from the same animal, taken during the luteal phase. The compact network of fibrils contrasts with the appearance of mucus during the ovulatory period (Plate 1). $\times 3500$.

Fig. 4. Cervical mucus of the same animal taken during the luteal phase. Note the similar diameters of the filaments and their glomerular extremities. $\times 8800$. 